\title{
THE COUNSEL OF BREAST CANCER IN THE FAMILY HEALTH STRATEGY
}

Marina E. Rocha', Diogo R. B. Araújo², Ronnycley K. M. B. Bras², Alysson H. Pereira J. Jacinto², Lorena T. Quirino³, Verônica S. Silva², Gabriel A. Maximo²

${ }^{1}$ Universidade Federal de Goiás - Goiânia (GO), Brazil.

União de Goyazes College - Trindade (GO), Brazil.

${ }^{3}$ Pontifícia Universidade Católica de Goiás - Goiânia (GO), Brazil.

Objective: To emphasize the role of the Family Health Strategy (FHS) team regarding early diagnosis and support to both the patient and the family in the treatments. Methodology: Non-systematized bibliographic research. We searched in articles and books for data on the subject addressed and its applicability in the work of the health team. Outcome: At the stage of detection and prevention of disease, professionals at the unit can advise on the importance of conducting self-examination, which is the active position that the Ministry of Health (MS) expects from professionals. The ESF nurse always during the consultations should offer instructions and talk about the importance of performing self-examination of the breasts. The actions of the FHT professionals extend to the post-diagnosis guidelines and their respective treatments. According to a study carried out with 90 nurses in 20 UBS in Diadema (SP) in 2013, 97\% of the nurses performed clinical examination of the breasts, $88 \%$ indicated the mammography each year, $75 \%$ guided the first examination from of the 40 years, and $52 \%$ promoted educational meetings. However, the orientation on age, time interval for mammography, and clinical examination, as well as active search for missing women, did not comply with the recommendations of MS. Conclusion: The increase in the number of cases of breast cancer reflects on the concern of individuals and planning of actions. Professionals recognize their role in the detection and prevention of breast cancer mainly through guidelines, consultations, and educational activities. It is imperative that the patient is treated in a holistic way and it is worth mentioning that the ESF teams have taken actions to control breast cancer, but there are some compliances between the actions performed and the MS proposals for the screening of this neoplasm that still need review. 